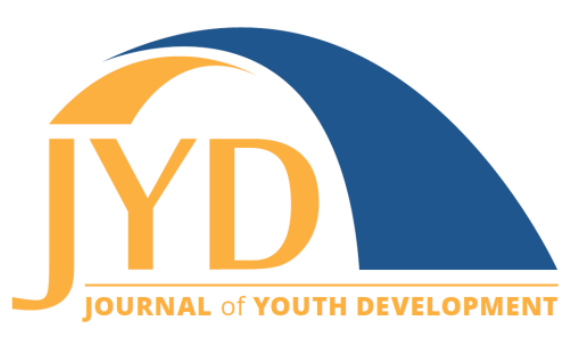

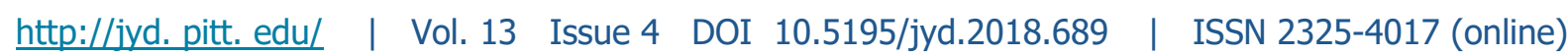

\title{
Book Review: Youth Development Principles and Practices in Out-of-School Time Settings
}

\section{Jill Young}

After School Matters

jill.young@afterschoolmatters.org

\begin{abstract}
Youth Development Principles and Practices in Out-of-school Time Settings (Witt \& Caldwell, 2018) is a comprehensive resource for students and professionals who work with youth in out-of-school time programs. The book weaves youth development theory and practice together so current and future practitioners can understand how to plan for, design, and evaluate youth programs that enable young people to thrive. Practitioners who work with adolescents will find the topics discussed relevant and the examples practical.
\end{abstract}

Key words: youth development, youth workers, youth development professionals

Theory and research demonstrate the important role youth professionals play in developing youth through the delivery of high quality out-of-school time (OST) programs so youth can thrive (Larson, Walker, Rusk, \& Diaz, 2015; Witt \& Caldwell, 2018). But many youth workers do not receive adequate training and do not collaboratively develop their professional skills, leading to limited opportunities to reflect, read research, or learn from other practitioners (Larson et al., 2015). Because of these challenges, understanding what positive youth development looks like in practice can be difficult. Youth Development Principles and Practices in Out-of-School Time Settings provides both the theories that guide youth development as well as what it looks like in practice for youth professionals.

The editors' aim was to "increase the capacity of students and professionals working with youth in OST contexts to more fully contribute to their development" (p. ix). The book draws upon the

(cc) EY New articles in this journal are licensed under a Creative Commons Attribution 4.0 License. This journal is published by the University Library System, University of Pittsburgh and is cosponsored by the University of Pittsburgh Press. The Journal of Youth Development is the official peer-reviewed publication of the National Association of Extension 4-H Agents and the National AfterSchool Association. 
Youth Development Principles and Practices

knowledge and experiences of experts in the field, who serve as authors or "voices" for each chapter.

The book is organized into five sections:

1. All About Youth

2. Developing Youths' Potential

3. Systematic Program Planning and Evaluation

4. The Role of Adults in the Lives of Youth

5. Diversity and Implications for Youth Development

The preface provides background on the beliefs that guide the book, how the book is organized and how to read it, and the backgrounds of the contributing voices. Section one provides an overview of youth, including principles of youth development, social and demographic youth trends, generational approaches, the adolescent brain, and a history of why and how youth services developed and evolved.

The second section of the book delves into positive youth development theories and how they work to develop youth potential in different types of youth programs, such as leisure, recreation, sports, nature, and arts. The third section of the book connects program planning with evaluation, providing an overview of what logic models are and why they are necessary for intentional program planning, as well as the basics of assessment and evaluation. The section ends with a chapter on designing programs to prevent attrition and instead structure deep, valued, and impactful experiences for youth.

Section four focuses on the role that adults play in the lives of young people, such as the importance of relationship-based programming, supporting youth development through family programming, and prioritizing youth engagement, voice, and opportunities for decision-making. The last section of the book highlights diverse youth and the role culture plays in OST and its implications, such as Latinx families, immigrant youth, LGBT, and youth with limited abilities. Finally, the editors conclude the book with a discussion about the knowledge, skills, and behaviors skilled youth professionals need. Each chapter ends with a complete list of references, discussion questions, and assignments that encourage further exploration of the chapter topics.

Because of the important role adults play as practitioners in facilitating youth development, this book is a much-needed resource. For students or new youth development practitioners, each 
Youth Development Principles and Practices

chapter should be read sequentially to gain a comprehensive understanding of youth development and how it manifests across different types of OST programs. Additionally, the book synthesizes the most relevant topics in youth development, providing real-life examples in each chapter to demonstrate the application of youth development principles.

The book is also very approachable for current practitioners who want to improve how they design and facilitate programs. These readers should read the first section, which establishes many key terms and principles related to youth development that appear throughout the book, and then read the chapters that are most relevant to their work. One limitation is that the examples focus primarily on adolescents and older youth who are preparing to enter adulthood. Therefore, this book may not be as pertinent for OST practitioners working with younger youth.

This comprehensive book presents an up-to-date and relevant resource for future and current youth development practitioners alike. The book covers youth development principles and foundational groundwork, how to develop youths' potential in various OST settings, how to systematically plan for and evaluate youth programs, the role of adults and families in youths' lives, and issues of diversity in youth development. The voices represented in the chapters are from respected experts in the field. This type of resource is needed to help formalize the youth development practitioner space.

\section{References}

Larson, R. W, Walker, K. C., Rusk, N., \& Diaz, L. B. (2015). Understanding youth development from the practitioner's point of view: A call for research on effective practice. Applied Developmental Science, 19(2), 74-86. doi:10.1080/10888691.2014.972558

Witt, P. A., \& Caldwell, L. L. (Eds.) (2018). Youth development principles and practices in out-of-school time settings ( $2^{\text {nd }}$ ed.). Urbana, IL: Sagamore-Venture. 